\title{
Genomic and metabolomic patterns segregate with responses to calcium and vitamin D supplementation
}

\author{
Manal O. Elnenaei, Rama Chandra, Tina Mangion and Caje Moniz* \\ Clinical Biochemistry Department, King's College Hospital, Denmark Hill, London SE5 9RS, UK \\ (Received 15 February 2010 - Revised 18 May 2010 - Accepted 5 July 2010 - First published online 23 August 2010)
}

\section{Abstract}

Inter-individual response differences to vitamin D and Ca supplementation may be under genetic control through vitamin D and oestrogen receptor genes, which may influence their absorption and/or metabolism. Metabolomic studies on blood and urine from subjects supplemented with $\mathrm{Ca}$ and vitamin D reveal different metabolic profiles that segregate with genotype. Genotyping was performed for oestrogen receptor 1 gene (ESR1) and vitamin D receptor gene (VDR) in fifty-six postmenopausal women. Thirty-six women were classified as low bone density as determined by a heel ultrasound scan and twenty women had normal bone density acting as 'controls'. Those with low bone density (LBD) were supplemented with oral Ca and vitamin D and were classified according to whether they were 'responders' or 'non-responders' according to biochemical results before and after therapy compared to controls receiving no supplementation. Metabolomic studies on serum and urine were done for the three groups at 0 and 3 months of therapy using NMR spectroscopy with pattern recognition. The 'non-responder' group showed a higher frequency of polymorphisms in the ESR1 (codons 10 and 325 ) and VDR (Bsm1 and Taq1), compared with to the 'responders'. The wild-type genotype for Fok1 was more frequent in those with LBD (70\%) compared with the control group (10\%). Distinctive patterns of metabolites were displayed by NMR studies at baseline and 3 months of post-treatment, segregating responders from non-responders and controls. Identification of potential 'non-responders' to vitamin D and Ca, before therapy, based on a genomic and/or metabolomic profile would allow targeted selection of optimal therapy on an individual basis.

Key words: Vitamin D receptor: Oestrogen receptor: Genotyping: Metabolomics

Recent advances in vitamin D research have transcended the preliminary concept that vitamin $\mathrm{D}$ is required only for $\mathrm{Ca}$ homoeostasis and maintenance of healthy bones. Apart from contributing to the development of osteomalacia and fragility fractures, vitamin D deficiency has been found to be detrimental to muscle function and may play a role in type 1 diabetes mellitus, hypertension, chronic infections and many common cancers ${ }^{(1-4)}$. Several reports have shown that vitamin $\mathrm{D}$ inadequacy is far more prevalent than previously thought particularly in postmenopausal women and specifically in those with osteoporosis and a history of fracture ${ }^{(5)}$. Fragility fractures are a major health problem globally with substantial morbidity and mortality ${ }^{(6,7)}$, and unless measures are taken to prevent osteoporosis, the costs associated with its prevention and treatment will pose a major socio-economic burden ${ }^{(8)}$.

Optimising peak bone mass and reducing subsequent postmenopausal loss depend on the interaction between genetic, hormonal, environmental and nutritional factors ${ }^{(9)}$. There has been an intense focus on identifying candidate genes for osteoporosis, fragility fractures and associated risk factors; yet in genome-wide searches, none of the candidate genes have been identified as important ${ }^{(10)}$. Less attention has been given to the more basic fundamental concepts related to inter-individual differences in $\mathrm{Ca}$ and vitamin D optimisation. Unravelling the basis to such core issues could be the simple cornerstone in the investigation of not only osteoporosis, but also in other diseases in which vitamin D deficiency is implicated.

Vitamin D insufficiency in the elderly, particularly, postmenopausal women, is associated with low bone mass due to secondary hyperparathyroidism and as a result of a higher incidence of fractures ${ }^{(11)}$. There have been various setbacks faced when supplementing this group. The first is the lack of consensus in determining the 'optimum dose $^{\text {(12) }}$. The second is patient compliance; but even if these issues were resolved, a bigger challenge is the lack of adequate response to oral vitamin $\mathrm{D}$ in a subset of patients. Ca and vitamin D absorption has been found in some studies to be dependent on certain vitamin $\mathrm{D}$ receptor (VDR) genotypes ${ }^{(13,14)}$. Moreover, a relationship between VDR genotype and oestrogen has been postulated

Abbreviations: ESR1, oestrogen receptor 1; LBD, low bone density; PTH, parathyroid hormone; VDR, vitamin D receptor; wt, wild-type.

*Corresponding author: C. Moniz, fax + 44203299 3140, email cajemoniz@nhs.net 
from the results of a study that examined the effects of $\mathrm{Ca}$ intake on bone mineral density in VDR-genotyped perimenopausal women ${ }^{(15)}$. Therefore, the question of satisfactory response to supplemental doses of $\mathrm{Ca}$ and vitamin $\mathrm{D}$ seems to be, like the rate of bone loss, under genetic control.

Identification of genetic factors without understanding their interaction with nutrients will confer little benefit in terms of prevention and treatment of osteoporosis or other related disorders ${ }^{(16)}$. Unlike genotype, diet and nutrition can be modified, and the arrival of the post-genomic era has enabled researchers to investigate the effects of nutrients on physiological functions at the molecular level $^{(17)}$. This will reveal how genetic variation and epigenetic events alter requirements for, and responses to, nutrients by profiling almost all of the products of metabolism in a single sample of blood or urine in a rapidly expanding research of 'metabolomics/metabonomics',(18) $\mathrm{H}^{3}$ NMR spectroscopy with multivariate data analysis has revolutionised the field of biomarker research, providing concurrent measurement of all hydrogen-containing metabolites in a biological fluid, hence providing a means of 'metabolic fingerprinting, (19).

The aim of the present study was to investigate the potential role of genetic variations in both the oestrogen receptor 1 (ESR1) and VDR in predicting response to $\mathrm{Ca}$ and vitamin $\mathrm{D}$ supplementation in a group of postmenopausal women with low bone density (LBD). NMR technology with pattern recognition was also employed in order to establish any treatment response segregation to biomarkers and possible correlation with the results of genotyping.

\section{Materials and methods}

\section{Patients}

A prospective case-controlled observational study on community dwelling postmenopausal women of Caucasian origin was conducted at the King's College Hospital Osteoporosis Clinic. The present study was conducted according to the guidelines laid down in the Declaration of Helsinki, and all procedures involving patients were approved by the Ethical Review Committee of the Hospital (LREC protocol no. 01-227). All the consecutive female patients above 50 years of age referred by their general practitioners to the clinic for a fragility fracture assessment using a heel ultrasound scan were offered to participate in the study after completing a witnessed written informed consent form.

All the participants completed a self-administered fracture risk questionnaire, and they had a quantitative heel ultrasound scan performed using the Lunar Achilles + GE Healthcare, Little Chalfont, Bucks, UK) on the left calcaneus. Fasting blood and urine samples were obtained for biochemical, genetic and metabolomic analyses. Subjects with any evidence of clinically significant hepatic or renal disorders, metastatic disease, multiple myeloma or any other conditions resulting in hypercalcaemia were excluded from the study.

Subjects classified as having a LBD, whether osteoporosis $(T$ score $<-2.5)$ or osteopenia $(T$ score $<-1 \cdot 0)$ on heel ultrasound, were started on $1200 \mathrm{mg}$ of oral $\mathrm{Ca}$ and 800 units of vitamin $\mathrm{D}$ in addition to their regular diets. Those with normal heel ultrasound did not receive any supplements and acted as controls. All the subjects were given lifestyle advice on avoidance of risk factors for osteoporosis. Blood and urine analyses were repeated after 3 months, and an additional sample was obtained for genotyping. The pre- and post-supplementation levels of vitamin D and parathyroid hormone (PTH) were assessed to determine response and whether the response to treatment is segregated towards specific genotypes. Compliance to treatment was assessed through direct questioning by the specialist nurse involved in the present study and biochemical evidence through the rise in urinary Ca excretion post-therapy (Table 1).

\section{Laboratory analysis}

Baseline and 3-month of biochemical analysis for renal, liver and bone profiles and urinary $\mathrm{Ca}$ were performed on the ADVIA 1200 (Siemens Healthcare Diagnostics, Camberley, Surrey, UK). PTH was measured on the Immulite 2000 (Siemens Healthcare Diagnostics) by using a twosite chemiluminescence immunoassay with antibodies to PTH (44-84 and 1-34). Vitamin D (25-hydroxyl) was measured using an ELISA kit (International Diagnostic

Table 1. Results of biochemical analysis in responders, non-responders and controls

(Mean values and standard deviations)

\begin{tabular}{|c|c|c|c|c|c|c|c|c|c|c|c|c|c|c|c|c|}
\hline & \multicolumn{8}{|c|}{ Baseline } & \multicolumn{8}{|c|}{3 months } \\
\hline & \multicolumn{2}{|c|}{$\begin{array}{c}\text { Serum Ca } \\
(\mathrm{mmol} / \mathrm{l})\end{array}$} & \multicolumn{2}{|c|}{$\begin{array}{c}\text { Urine Ca } \\
\text { (mmol/ } \\
\text { mmol creat) }\end{array}$} & \multicolumn{2}{|c|}{$\begin{array}{l}\text { Vitamin D } \\
(\mu \mathrm{g} / \mathrm{l})\end{array}$} & \multicolumn{2}{|c|}{ PTH (pg/l) } & \multicolumn{2}{|c|}{$\begin{array}{c}\text { Serum Ca } \\
(\mathrm{mmol} / \mathrm{l})\end{array}$} & \multicolumn{2}{|c|}{$\begin{array}{l}\text { Urine } \mathrm{Ca} \\
\text { (mmol/ } \\
\text { mmol creat) }\end{array}$} & \multicolumn{2}{|c|}{$\begin{array}{l}\text { Vitamin D } \\
(\mu \mathrm{g} / \mathrm{l})\end{array}$} & \multicolumn{2}{|c|}{ PTH (pg/l) } \\
\hline & Mean & SD & Mean & SD & Mean & SD & Mean & SD & Mean & SD & Mean & SD & Mean & $\mathrm{SD}$ & Mean & SD \\
\hline Responders (n 22) & $2 \cdot 39$ & 0.04 & 3.0 & $2 \cdot 0$ & $17 \cdot 6$ & $5 \cdot 0$ & $51 \cdot 1$ & 12 & $2 \cdot 41$ & 0.03 & $7 \cdot 8$ & 3.5 & $26 \cdot 5$ & 10 & 28 & 8 \\
\hline Non-responders $(n 14)$ & 2.34 & 0.04 & $2 \cdot 9$ & 2.5 & $19 \cdot 2$ & $5 \cdot 6$ & $36 \cdot 2$ & 18 & $2 \cdot 36$ & 0.02 & 4.0 & $2 \cdot 2$ & 22.5 & 8 & 32.6 & 12 \\
\hline Control (n 20) & 2.45 & 0.03 & $2 \cdot 8$ & $2 \cdot 0$ & $22 \cdot 8$ & 4.8 & 33.1 & 15 & 2.44 & 0.03 & 3.2 & 1.9 & 24.8 & 10 & 29.8 & 12 \\
\hline
\end{tabular}

creat, Creatine; PTH, parathyroid hormone-intact. 
Systems, St Joseph, MI, USA). Within and between CV for PTH and vitamin D were less than $8 \%$ for both analytes.

\section{Allelic discrimination}

Whole blood in vacutainers was stored at $4^{\circ} \mathrm{C}$ for up to 2 weeks before DNA was isolated using a Promega Genomic (Southampton, UK) DNA Wizard Isolation kit. The DNA was then aliquoted and stored at $-20^{\circ} \mathrm{C}$ until required. Genotyping was performed for the human ESR1 (codons 10 and 325) and VDR (Fok1, Bsm1 and Taq1), using pairs of dual labelled probes, one labelled with FAM and TAMRA to detect one allele, and the other labelled with VIC and TAMRA to detect the other allele.

The genetic variations analysed were oestrogen receptor $\mathrm{T} / \mathrm{C}$ codon 10 and $\mathrm{C} / \mathrm{G}$ codon 325, VDR C/T exon 2 (Fok1), G/A intron 8 (Bsm1) and T/C exon 9 (Taq1).

Artificial templates were constructed for both the genotypes of each polymorphism to act as controls. A common forward primer which spanned the whole forward primer and the $5^{\prime}$ part of the shared region of the probe sequence and the unique reverse primer for each genotype spanning from the shared region of the probe sequence to the $3^{\prime}$ end of the reverse primer, creating an overlap area, was incubated with Klenow DNA polymerase. This produced a piece of doublestranded DNA suitable for use as a control template. Sigma Genosys (Haverhill, UK) supplied the oligonucleotides. After thirty-five cycles of amplification, the results were analysed using the allelic discrimination protocol of the ABI PRISM 7700 Sequence Detector and scored as wild-type (wt) heterozygote or homozygous/alternate allele. All probes, primers, Universal master mix, optical plates and caps were obtained from Applied Biosystems (Foster City, CA, USA).

\section{Biomarker studies}

$H-N M R$ on urine samples for NMR and pattern recognition. Before NMR spectroscopic analysis, $1 \mathrm{ml}$ urine samples were lyophilised and reconstructed in $1 \mathrm{ml}$ of sodium-phosphate buffer ( $\mathrm{pH} 6 \cdot 0$, made up with $\left.{ }^{2} \mathrm{H}_{2} \mathrm{O}\right) \quad$ containing $1 \mathrm{~mm}$-sodium-trimethylsilyl$\left(2,2,3,3,-{ }^{2} \mathrm{H}_{4}\right)$-L-propionate as an internal standard. NMR spectra were recorded in triplicate in a fully automated manner on a Varian UNITY $400 \mathrm{MHz}$ spectrometer using a proton NMR set-up operating at a temperature of $293 \mathrm{~K}$. Free induction decays were collected as $64 \mathrm{~K}$ data points with a spectral width of $8.000 \mathrm{~Hz} ; 45^{\circ}$ pulses were used with an acquisition time of $4.10 \mathrm{~s}$ and a relaxation delay of $2 \mathrm{~s}$. The spectra were acquired by accumulation of 128 free induction decays. The signal of the residual water was removed by a pre-saturation technique in which the water peak was irradiated with a constant frequency during $2 \mathrm{~s}$ before the acquisition pulse. The spectra were processed using the standard Varian software.
An exponential window function with a line broadening of $0.5 \mathrm{~Hz}$ and a manual baseline correction was applied to all the spectra. After referring to the internal NMR reference (sodium-trimethylsilyl-(2,2,3,3,- $\left.{ }^{2} \mathrm{H}_{4}\right)$-L-propionate $5=0 \cdot 0$ ), line listings were prepared using the standard Varian NMR software. To obtain these listings, all lines in the spectra above a threshold corresponding to about three times the signal-to-noise ratio were collected and converted to a data file suitable for multivariate analysis applications.

$H$-NMR on serum samples for NMR and pattern recognition. Before NMR spectroscopic analysis, serum samples were deproteinised either by filtration or by extraction against isopropanol.

Filtration. Before filtration, the filters with a molecular mass cut-off value of $10 \mathrm{kDa}$ (Microcon YM-10; Millipore, Bedford, MA, USA) were spin rinsed with $0.5 \mathrm{ml}$ of $0.05 \mathrm{M}-\mathrm{NaOH}$ followed by $2 \times 0.5 \mathrm{ml}$ of deionised water to avoid contamination of the ultra-filtrate with glycerine. Deproteinisation of the plasma samples by filtration was performed by centrifugation (1h at $10000 \mathrm{rpm}$ ) of $0.5 \mathrm{ml}$ plasma over a filter followed by the centrifugation (1h at $10000 \mathrm{rpm}$ ) of $0.5 \mathrm{ml}$ deionised water in order to rinse the filtration membrane. Before NMR spectroscopic analysis, filtrates were freeze dried and reconstructed in $750 \mu \mathrm{l}$ of sodium-phosphate buffer ( $\mathrm{pH}$ 6.0, made up with $\left.{ }^{2} \mathrm{H}_{2} \mathrm{O}\right)$ containing $1 \mathrm{~mm}$-sodium-trimethylsilyl$\left(2,2,3,3,-{ }^{2} \mathrm{H}_{4}\right)$-L-propionate as an internal standard.

Extraction. Plasma samples were deproteinised by extraction of $100 \mu \mathrm{l}$ plasma with $600 \mu \mathrm{l}$ isopropanol. After centrifugation $(5 \mathrm{~min}$ at $10000 \mathrm{rpm})$, the supernatant was isolated and concentrated to dryness. The residue was dissolved in $750 \mu \mathrm{l}$ methyl 9,12-epoxy-octadecanoate (MeOD) before NMR analysis.

NMR spectroscopy. NMR spectra were recorded in triplicate in a fully automated manner on a Varian UNITY $400 \mathrm{MHz}$ spectrometer using a proton NMR set-up operating at a temperature of $293 \mathrm{~K}$. Free induction decays were collected as $64 \mathrm{~K}$ data points with a spectral width of $8.000 \mathrm{~Hz} ; 45^{\circ}$ pulses were used with an acquisition time of $4 \cdot 10 \mathrm{~s}$ and a relaxation delay of $2 \mathrm{~s}$. The spectra were acquired by the accumulation of 512 free induction decays. In the case of ${ }^{2} \mathrm{H}_{2} \mathrm{O}$ samples, the signal of the residual water was removed by a pre-saturation technique in which the water peak was irradiated with a constant frequency during $2 \mathrm{~s}$ before the acquisition pulse.

The spectra were processed using the standard Varian software. An exponential window function with a line broadening of $0.5 \mathrm{~Hz}$ and a manual baseline correction was applied to all the spectra.

After referring to the internal NMR reference (sodiumtrimethylsilyl- $\left(2,2,3,3,-{ }^{2} \mathrm{H}_{4}\right)$-L-propionate $8=0.00$ or MeOD $5=3 \cdot 30$ ), line listings are prepared using the standard Varian NMR software. To obtain these listings, all lines in the spectra above a threshold corresponding to about three times the signal-to-noise ratio were collected and converted to a data file suitable for multivariate analysis applications. 


\section{Data analysis}

The mean levels of treatment and control groups were compared using $t$ tests. A drop of more than $26 \%$ of PTH after 3 months of therapy was calculated as a principle criterion of response to therapy. This was based on the total variation (analytical and biological) of the PTH assay. Those with a decrease greater than $26 \%$ were classified as 'responders' to treatment, and those showing a decrease of less than this or a paradoxical increase in PTH were classified as 'nonresponders'. Genotype allele frequencies were examined in control, 'responder' and 'non-responder' groups.

The NMR spectra were processed using the standard Varian software and converted to a data file suitable for multivariate analysis applications (multivariate data analysis). Small differences of comparable signals in different NMR spectra were aligned. The respective datasets were used for multivariate data analysis in Matlab (v6.5; The Mathworks, Natick, MA, USA). Techniques that were applied were, among others, principal component analysis, principal component discrimination analysis and partial least squares discriminant analysis. In principal component analysis, data are transformed from a large set of related variables (NMR signals) to a smaller set of uncorrelated variables. These newly created variables are called principal components. Each principal components forms an axis in multidimensional space, and the calculated distance of an object to this axis is termed a score. Supervised methods such as partial least squares discriminant analysis and principal component discrimination analysis are more powerful tools, which use additional information on the dataset such as biochemical or clinical data to identify differences between pre-defined groups. In principal component discrimination analysis, the scores from principal component analysis are used as a starting point for linear discriminant analysis. The discriminant analysis works by combining the principal components in such a way that differences between pre-defined groups are maximised ${ }^{(20)}$.

\section{Results}

One hundred and eight subjects were presented to the clinic during the study period. Of these, fifty-six subjects fulfilled the inclusion criteria and were included in the study.

The mean age of the subjects was 70 years (age range 50-87 years). Thirty-six cases were found to have LBD ( $T$ score $<-1 \cdot 0$ ) on heel ultrasound and were started on $\mathrm{Ca}$ and vitamin $\mathrm{D}_{3}$ supplements, while twenty cases had normal heel ultrasound and were treated as controls.

Among the thirty-six cases, twenty-two subjects were classified as responders (mean PTH 51.1 and 28 at baseline and 3 months, respectively) and fourteen were classified as non-responders (mean PTH 36.2 and 32.6 at baseline and 3 months, respectively) to $\mathrm{Ca} /$ vitamin $\mathrm{D}$ therapy (Table 1 ).

Table 1 shows the results of biochemical analysis in responders, non-responders of $\mathrm{Ca}$ and vitamin $\mathrm{D}$ supplementation and control subjects. Mean serum total $\mathrm{Ca}$ levels showed no change from baseline, but mean vitamin $\mathrm{D}$ levels increased by the end of the treatment period compared with baseline, particularly in the responder group. Mean urinary $\mathrm{Ca}$ excretion increased in both the groups but more in the responder group compared to non-responders $(7.8 v .4 .0 \mathrm{mmol} / \mathrm{mmol}$ creatinine).

\section{Allelic discrimination study}

Table 2 shows the genotype in responders, non-responders and controls. For example, of the total number of responders analysed, $41 \%$ have the non-polymorphic ESR1 (codon 10) $\mathrm{T} / \mathrm{T}$ genotype; $36 \%$ are heterozygous and $23 \%$ are homozygous for the ESR1 (codon 10) polymorphism. Accordingly, the frequency of the wt $\mathrm{T}$ allele among the responders is $59 \%$ and that of the polymorphic $\mathrm{C}$ allele is $41 \%$ (Table 3). A subject with the ESR1 (codon 10) $\mathrm{T} / \mathrm{T}$ genotype has a $63 \%$ chance of being a responder, $22 \%$ chance of being a non-responder and $15 \%$ chance of being a vitamin D-sufficient control.

For the VDR Fok1 gene, the wt genotype was found in only $10 \%$ of the control subjects compared with nearly

Table 2. Results of genotyping in responders, non-responders and controls as percentages

\begin{tabular}{lllllll}
\hline Subjects & Genotypes & HER 10 & HER 325 & VDR Bsm1 & VDR Fok1 & VDR Taq1 \\
\hline Responders $(n$ 22) & Hom & $\mathrm{C} / \mathrm{C}-23$ & $\mathrm{G} / \mathrm{G}-5$ & $\mathrm{~A} / \mathrm{A}-48$ & $\mathrm{C} / \mathrm{C}-14$ & $\mathrm{C} / \mathrm{C}-28 \cdot 5$ \\
& Het & $\mathrm{T} / \mathrm{C}-41$ & $\mathrm{C} / \mathrm{G}-36$ & $\mathrm{G} / \mathrm{A}-33$ & $\mathrm{~T} / \mathrm{C}-18$ & $\mathrm{~T} / \mathrm{C}-28.5$ \\
& WT & $\mathrm{T} / \mathrm{T}-36$ & $\mathrm{C} / \mathrm{C}-59$ & $\mathrm{G} / \mathrm{G}-19$ & $\mathrm{~T} / \mathrm{T}-68$ & $\mathrm{~T} / \mathrm{T}-43$ \\
\multirow{5}{*}{ Non-responders $(n$ 14) } & ND & - & - & - & - & - \\
& Hom & $\mathrm{C} / \mathrm{C}-36$ & $\mathrm{G} / \mathrm{G}-14$ & $\mathrm{~A} / \mathrm{A}-23$ & $\mathrm{C} / \mathrm{C}-23$ & $\mathrm{C} / \mathrm{C}-31$ \\
& Het & $\mathrm{T} / \mathrm{C}-50$ & $\mathrm{C} / \mathrm{G}-29$ & $\mathrm{G} / \mathrm{A}-38$ & $\mathrm{~T} / \mathrm{C}-8$ & $\mathrm{~T} / \mathrm{C}-38$ \\
\multirow{3}{*}{ Controls $(n$ 10) } & WT & $\mathrm{T} / \mathrm{T}-14$ & $\mathrm{C} / \mathrm{C}-57$ & $\mathrm{G} / \mathrm{G}-38$ & $\mathrm{~T} / \mathrm{T}-69$ & $\mathrm{~T} / \mathrm{T}-31$ \\
& ND & - & - & 1 & & - \\
& Hom & $\mathrm{C} / \mathrm{C}-10$ & - & $\mathrm{A} / \mathrm{A}-20$ & $\mathrm{C} / \mathrm{C}-30$ & $\mathrm{C} / \mathrm{C}-23$ \\
& Het & $\mathrm{T} / \mathrm{C}-80$ & $\mathrm{C} / \mathrm{G}-40$ & $\mathrm{G} / \mathrm{A}-50$ & $\mathrm{~T} / \mathrm{C}-60$ & $\mathrm{~T} / \mathrm{C}-44$ \\
& WT & $\mathrm{T} / \mathrm{T}-10$ & $\mathrm{C} / \mathrm{C}-60$ & $\mathrm{G} / \mathrm{G}-30$ & $\mathrm{~T} / \mathrm{T}-10$ & $\mathrm{~T} / \mathrm{T}-33$ \\
& ND & - & - & - & - &
\end{tabular}

HER, human oestrogen receptor; VDR, vitamin D receptor; Hom, homozygous; C, cytosine; G, guanine; A, adenine; T, thymine; het, heterozygous; WT, wild type; ND, not done. 
Table 3. Genotyping, allele frequency and probability of being responders, non-responders and controls

\begin{tabular}{|c|c|c|c|}
\hline Genotype & Responders (\%) & Non-responders (\%) & Controls (\%) \\
\hline \multicolumn{4}{|l|}{ HER 10} \\
\hline$T / T$ & 63 & 22 & 15 \\
\hline $\mathrm{T} / \mathrm{C}$ & 35 & 30 & 35 \\
\hline $\mathrm{C} / \mathrm{C}$ & 33 & 52 & 15 \\
\hline \multicolumn{4}{|l|}{ Allele } \\
\hline T & 59 & 39 & 50 \\
\hline C & 41 & 61 & 50 \\
\hline \multicolumn{4}{|l|}{ HER 325} \\
\hline $\mathrm{C} / \mathrm{C}$ & 34 & 33 & 34 \\
\hline$C / G$ & 34 & 28 & 38 \\
\hline $\mathrm{G} / \mathrm{G}$ & 26 & 74 & 0 \\
\hline \multicolumn{4}{|l|}{ Allele } \\
\hline C & 77 & 71 & 80 \\
\hline G & 23 & 29 & 20 \\
\hline \multicolumn{4}{|l|}{ VDR Bsm1 } \\
\hline $\mathrm{G} / \mathrm{G}$ & 41 & 33 & 26 \\
\hline $\mathrm{G} / \mathrm{A}$ & 27 & 31 & 41 \\
\hline $\mathrm{A} / \mathrm{A}$ & 31 & 37 & 32 \\
\hline \multicolumn{4}{|l|}{ Allele } \\
\hline $\mathrm{G}$ & 64 & 58 & 55 \\
\hline A & 36 & 42 & 45 \\
\hline \multicolumn{4}{|l|}{ VDR Fok1 } \\
\hline$T / T$ & 46 & 47 & 7 \\
\hline $\mathrm{T} / \mathrm{C}$ & 21 & 9 & 70 \\
\hline $\mathrm{C} / \mathrm{C}$ & 21 & 34 & 45 \\
\hline \multicolumn{4}{|l|}{ Allele } \\
\hline $\mathrm{T}$ & 77 & 73 & 40 \\
\hline C & 23 & 27 & 60 \\
\hline \multicolumn{4}{|l|}{ VDR Taq1 } \\
\hline$T / T$ & 40 & 29 & 31 \\
\hline $\mathrm{T} / \mathrm{C}$ & 25 & 35 & 40 \\
\hline $\mathrm{C} / \mathrm{C}$ & 34 & 38 & 28 \\
\hline \multicolumn{4}{|l|}{ Allele } \\
\hline$T$ & 57 & 50 & 56 \\
\hline C & 43 & 50 & 44 \\
\hline
\end{tabular}

HER, human oestrogen receptor; T, thymine; C, cytosine; G, guanine; VDR, vitamin D receptor; A, adenine.

$70 \%$ in both LBD groups (responders and non-responders) (Table 2). Table 3 shows that a subject with a heterozygous genotype for Fok1 (T/C) has a $70 \%$ probability of belonging to the control group, and a 21 and $9 \%$ probability of being a responder and non-responder, respectively. Thus, a subject with LBD who is heterozygous for the VDR Fok1 genotype may have an increased chance of being responsive compared with a similar subject who is homozygous for the VDR Fok1 genotype.

Table 4 shows the allelic frequencies in the various genetic markers tested in responder, non-responder and control groups as compared to previously published data in the general population ${ }^{(21)}$.

\section{Biomarker study}

A difference profile was set up for predicting the responsiveness to vitamin $\mathrm{D} / \mathrm{Ca}$ therapy in our patient group. This was done by first providing a normalised set of positions and corresponding signal intensities of spectral lines of one or more NMR spectra recorded from metabolites in urine and serum of several osteoporotic subjects known to respond to vitamin D/Ca therapy, and compared to a second set of positions and corresponding signal intensities recorded before therapy. The same was done for the non-responder and control groups. Multivariate data analysis was used to visualise differences related to the different subject groups in these spectra, and difference profiles were set up as shown in Fig. 1.

Fig. 2 shows that controls, responders and nonresponders segregate into definable groups both at 0 and 3 months following therapy when analysed by principal component discrimination analysis scores.

When partial least squares discriminant analysis was used for model building, responders, non-responders and controls segregated into well-defined groups. When subjects 69 and 76 were initially excluded from the model, and then reintroduced after its construction, they were found to be predicted as a responder and non-responder, respectively (image not shown), which coincided with the biochemistry results.

\section{Discussion}

The present study has shown potentially significant differences at the genetic level between patients who were found to be responsive to oral $\mathrm{Ca}$ and vitamin $\mathrm{D}$ supplementation and those classified as 'non-responders', after 3 months of supplementation. Compared with 'non-responders', as well as previously published data on allele frequencies, those who were 'responders' had lower frequencies of ESR1 (codons 10 and 325) and VDR (Taq1 and Bsm1) polymorphisms. Both the groups (LBD) had a higher incidence of the wt Fok1 genotype compared with the control group. The significance of these genotypic findings came into greater perspective following discriminant analysis in our NMR studies which showed distinctive patterns of metabolites at both baseline and following 3 months of treatment, segregating responders from non-responders and controls. While both the molecular

Table 4. Gene frequency among responders, non-responders and controls and comparison with the literature ${ }^{(21)}$

\begin{tabular}{lcccc}
\hline & \multicolumn{3}{c}{ Gene frequency in the present study } & \\
\cline { 2 - 4 } Genotypes & Responders $(n$ 22) & Non-responders $(n$ 14) & Controls $(n$ 20) & Previously published frequency \\
\hline HER 10 & 0.41 & 0.60 & 0.50 & 0.48 \\
HER 325 & 0.23 & 0.29 & 0.20 & 0.22 \\
VDR Bsm1 & 0.36 & 0.42 & 0.45 & 0.42 \\
VDR Fok1 & 0.23 & 0.27 & 0.60 & 0.37 \\
VDR Taq1 & 0.43 & 0.50 & 0.44 & 0.41 \\
\hline
\end{tabular}

HER, human oestrogen receptor; VDR, vitamin D receptor. 


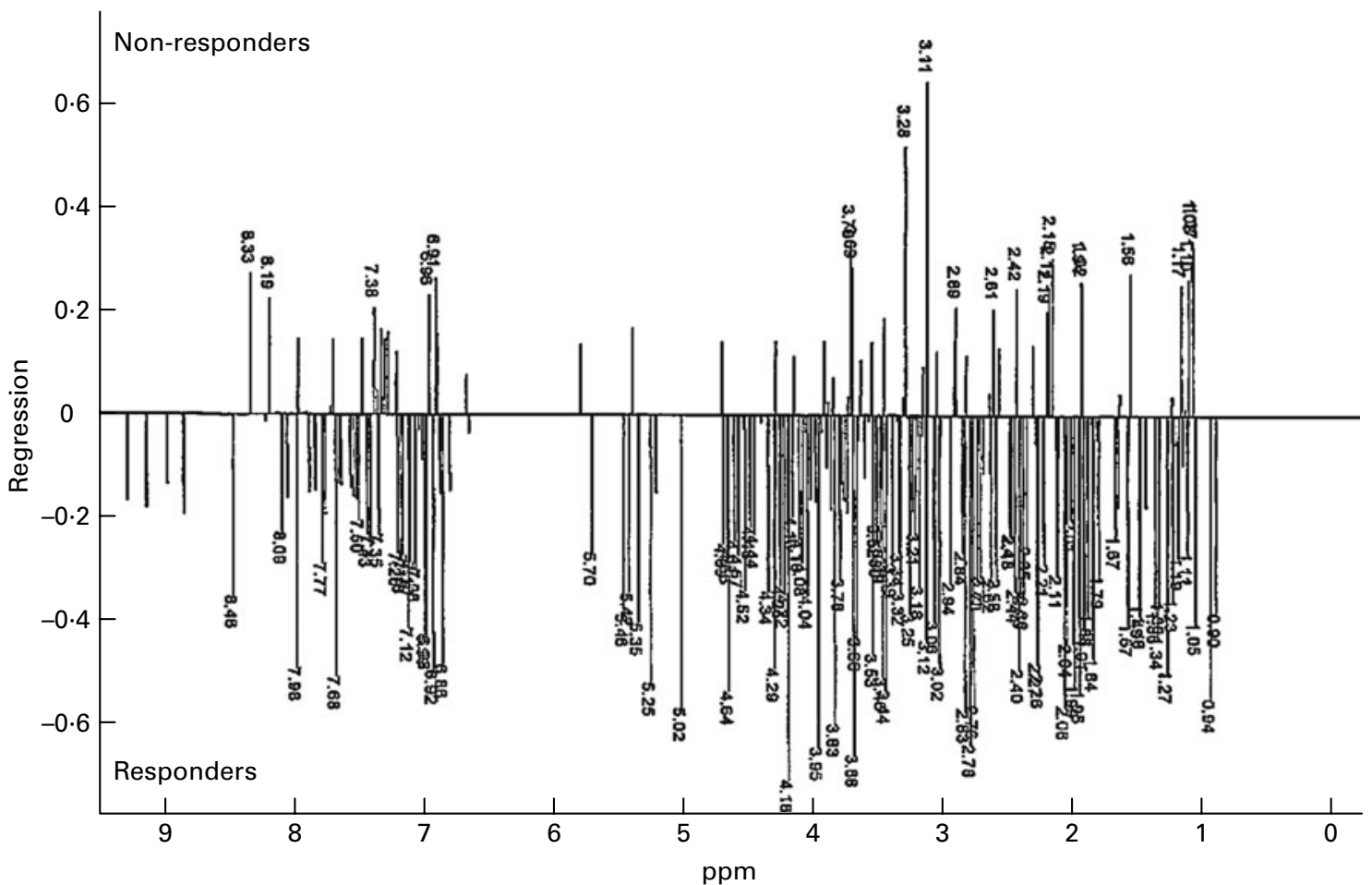

Fig. 1. Principal component discrimination analysis factor spectrum responders $v$. non-responders at 0 month. ppm, Parts per million.

genetics and the role of nutrition in bone health are currently very vibrant and important research areas in their own right, we have for the first time been able to demonstrate the interaction between genetic and nutrition factors by the segregation of our groups into genetically and 'nutrigenomically' concordant entities.
There is an ongoing debate on recommendations of daily allowance for vitamin $\mathrm{D}$ as well as the optimal serum concentration to achieve efficacy. A study on a group of postmenopausal African American women found that the current recommended daily allowance of vitamin D of $400-600 \mathrm{IU} / \mathrm{d}$ did not optimise vitamin D

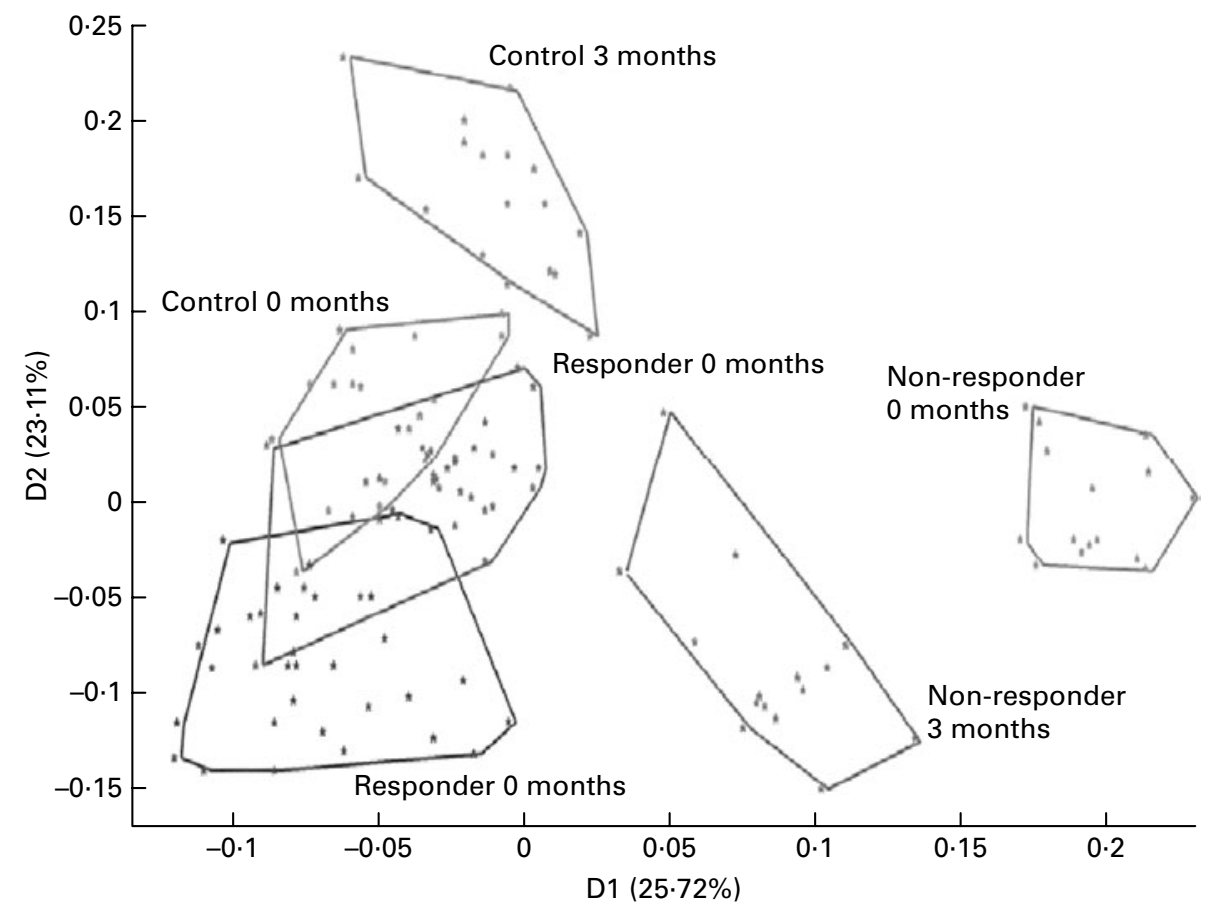

Fig. 2. Principal component discrimination analysis score plot shows that controls, responders and non-responders segregate into definable groups both at 0 and 3 months following therapy. D1 and D2, discriminant 1 and 2 plots as calculated by the principal component discriminant analysis software. 
levels in a subgroup of this population ${ }^{(22)}$. This suggests a genetic basis for vitamin $\mathrm{D}$ absorption and/or metabolism. However, there has been paucity of research in defining genetic makers for $\mathrm{Ca}$ and vitamin $\mathrm{D}$ absorption. Studies in this respect have focused almost exclusively on the VDR gene within different age groups and races. Nieves et $a l .{ }^{(23)}$ found that the Fok1 polymorphism of the VDR gene may alter the response of postmenopausal African American women to vitamin D supplementation, with response (as measured by the degree of PTH suppression) being greatest in those with the wt genotype. Our LBD group had a much lower frequency of the Fok1 polymorphism compared with controls, an unexpected finding warranting further investigation. Gennari et al. ${ }^{(24)}$ found that intestinal $\mathrm{Ca}$ absorption was significantly lower in BB (Bsm1) and tt (Taq1) genotypes in postmenopausal Caucasian women, which is in partial agreement with the present finding of higher allelic frequencies of the Taq1 gene in 'non-responders'. Isotopic Ca absorption in adolescents showed that while $\mathrm{Ca}$ absorption was $20 \%$ higher in the Fok1 FF group compared with the ff group, the former group showed slightly lower vitamin D levels ${ }^{(25)}$. This finding emphasises the complexity of the genetic control on $\mathrm{Ca}$ and vitamin D absorption and metabolism; but while mechanisms may be difficult to unravel, identification of genetic patterns and associations pave the way to a more personalised approach to therapy.

Several interactions between the vitamin D and the oestrogen endocrine system have been described ${ }^{(26-28)}$. Moreover, an association between ESR1 and VDR genotypes with respect to bone density and/ or fracture susceptibility has been established ${ }^{(29,30)}$. However, to our knowledge, there have been no investigations reported on ESR1 gene variations in relation to $\mathrm{Ca}$ or vitamin $\mathrm{D}$ metabolism. We have demonstrated in the present study that the more favourable wt ESR1 genotypes appear to have a positive effect on vitamin D and Ca absorption and metabolism. Oestrogen receptors are extensively expressed in the gastrointestinal tract, and oestrogen has been found to increase VDR gene transcript level, protein expression and endogenous 25-hydroxyvitamin $\mathrm{D}_{3}$ bioactivity in rat colonic mucosa, which may suggest that some of the oestrogen activities in the colonic mucosa could be mediated, at least in part, by an increase in colonic mucosa responsiveness to endogenous $1,25(\mathrm{OH})_{2} \mathrm{D}_{3}^{(31)}$. The more favourable wt VDR (both Taq1 and Bsm1) genotype also appears to have a positive effect on response to vitamin $\mathrm{D}$ and $\mathrm{Ca}$ intake as seen in the present study. The mechanism by which any differences in the VDR alleles may account for changes in $\mathrm{Ca}$ homoeostasis is not clear; differences in parathyroid gland regulation have been found to be associated with VDR polymorphisms ${ }^{(32-34)}$.

Understanding the inter-relationships among genes, gene products and dietary habits is fundamental to identifying those who will benefit most from intervention strategies. Unravelling the multitude of nutrigenomic and metabolomic patterns that arise from the ingestion of foods or their bioactive components provides insights into a tailored approach to diet and supplementation ${ }^{(35)}$. Hence, nutrigenomics is destined within the next decade to identify complex associations between nutrients and the expression of thousands of genes with simultaneous changes in an equivalent number of metabolites ${ }^{(18)}$. With the use of such technology, we were able to find distinct patterns of segregation between controls, responders and non-responders of $\mathrm{Ca}$ and vitamin $\mathrm{D}$ supplementation in osteoporotic patients. This finding was particularly encouraging given the relatively small number of patients. Moreover, it was possible to categorise the patients at baseline, before commencement of therapy, into quite distinct entities. The latter could pave the way for a marker(s) that will enable the development of a pre-treatment workup to identify those who would not respond to usual levels of $\mathrm{Ca}$ and vitamin D supplementation.

Preliminary analysis of our 'NMR fingerprinting' has suggested that folate and vitamin B metabolism is implicated in $\mathrm{Ca}$ and vitamin $\mathrm{D}$ status and response to supplementation (data not shown). This finding provides tremendous potential for detailed evaluation of the metabolic pathways between $\mathrm{Ca} /$ vitamin $\mathrm{D}$ and folate/vitamin $\mathrm{B}_{12}$, including their interaction in osteoporosis and treatment responses. It is worth noting that allelic polymorphisms in the gene encoding methylenetetrahydrofolate have been associated with reduced bone mineral density in postmenopausal Japanese women ${ }^{(36)}$ and early postmenopausal Danish women ${ }^{(37)}$, suggesting a role for the folate metabolic pathway in bone health. However, at this stage, speculation on deficiency and how micronutrients interact in this population would be premature and further investigation is warranted.

The main limitations of the present study were the small sample size and the fact that those who had osteopenia were not segregated from those who had osteoporosis; both groups were defined as 'low bone mass'. It is notable, however, that a lower threshold than that defined by the WHO for diagnosing osteoporosis has been suggested for quantitative heel ultrasound ${ }^{(38)}$. Despite the limitations, we have demonstrated links between genetic and nutritional factors as evidenced by the segregation of responders, non-responders and controls into groups that can be identified by both genetic and nutrigenomic profiles. This has been an observational study ${ }^{(39)}$, and further work is warranted on a larger number of subjects for the confirmation of the findings. Extension of the NMR work is also necessary, and further investigation of the potentially interesting metabolites may provide exciting opportunities for the development of a simple laboratory diagnostic test for the provision of a patient-tailored approach to treatment. 


\section{Acknowledgements}

We would like to thank Johannes Van Nesselrooij and Robert-Jan A. N. Lamers from TNO Nutrition and Food Research, The Netherlands, for their assistance in the biomarker study. The authors declare that there are no conflicts of interest. The present research received no specific grant from any funding agency in the public, commercial or not-for-profit sectors. We would like to thank C. M. for design of the study, patient recruitment and genomics studies; M. O. E. for data analysis and manuscript writing; R. C. for clinical and biochemical studies and sample collections; nurse T. M. for clinical study and sample collections.

\section{References}

1. Arvold DS, Odean MJ, Dornfeld MP, et al. (2009) Correlation of symptoms with vitamin D deficiency and symptom response to cholecalciferol treatment: a randomized controlled trial. Endocr Pract 15, 203-212.

2. Teegarden D \& Donkin SS (2009) Vitamin D: emerging new roles in insulin sensitivity. Nutr Res Rev 22, 82-92.

3. Artaza JN, Mehrotra R \& Norris KC (2009) Vitamin D and the cardiovascular system. Clin J Am Soc Nephrol 4, 1515-1522.

4. Cross HS, Nittke T \& Peterlik M (2009) Modulation of vitamin D synthesis and catabolism in colorectal mucosa: a new target for cancer prevention. Anticancer Res 29, 3705-3712.

5. Adami S, Giannini S, Bianchi G, et al. (2009) Vitamin D status and response to treatment in post-menopausal osteoporosis. Osteoporos Int 20, 239-244.

6. Ray NF, Chan JK, Thamer M, et al. (1997) Medical expenditures for the treatment of osteoporotic fractures in the United States in 1995: report from the National Osteoporosis Foundation. J Bone Miner Res 12, 24-35.

7. Cummings SR \& Melton LJ (2002) Epidemiology and outcomes of osteoporotic fractures. Lancet 359, 1761-1767.

8. World Health Organisation (2003) Prevention and Management of Osteoporosis. World Health Organisation Technical Report Series no. 921. Geneva: WHO.

9. Baldock PA \& Eisman JA (2004) Genetic determinants of bone mass. Curr Opin Rheumatol 16, 450-456.

10. Richards JB, Rivadeneira F, Inouye M, et al. (2008) Bone mineral density, osteoporosis, and osteoporotic fractures: a genome-wide association study. Lancet 371, 1505-1512.

11. Bruyère $O$, Malaise $O$, Neuprez A, et al. (2007) Prevalence of vitamin D inadequacy in European postmenopausal women. Curr Med Res Opin 23, 1939-1944.

12. Bischoff-Ferrari HA, Giovannucci E, Willett WC, et al. (2006) Estimation of optimal serum concentrations of 25-hydroxyvitamin D for multiple health outcomes. Am J Clin Nutr 84, $18-28$.

13. Dawson-Hughes B, Harris SS \& Finneran S (1995) Calcium absorption on high and low calcium intakes in relation to vitamin D receptor genotype. J Clin Endocrinol Metab 80, 3657-3661.

14. Wishart JM, Horowitz M, Need AG, et al. (1997) Relations between calcium intake, calcitriol, polymorphisms of the vitamin $\mathrm{D}$ receptor gene, and calcium absorption in premenopausal women. Am J Clin Nutr 65, 798-802.

15. Willing M, Sowers M, Aron D, et al. (1998) Bone mineral density and its change in white women: estrogen and vitamin D receptor genotypes and their interaction. $J$ Bone Miner Res 13, 695-705.
16. Wood RJ \& Fleet JC (1998) The genetics of osteoporosis: vitamin D receptor polymorphisms. Annu Rev Nutr 18, 233-258.

17. Ordovas JM \& Mooser V (2004) Nutrigenomics and nutrigenetics. Curr Opin Lipidol 15, 101-108.

18. Zeisel SH (2007) Nutrigenomics and metabolomics will change clinical nutrition and public health practice: insights from studies on dietary requirements for choline. Am J Clin Nutr 86, 542-548.

19. Whitfield PD, German AJ \& Noble PJ (2004) Metabolomics: an emerging post-genomic tool for nutrition. Br J Nutr $\mathbf{9 2}$, $549-555$.

20. Lindon JC, Nicholson JK, Holmes E, et al. (2000) Metabonomics: metabolic processes studies by NMR spectroscopy of biofluids combined with pattern recognition. Concepts Magn Reson 12, 289-320.

21. Dvornyk V, Long JR, Xiong DH, et al. (2004) Current limitations of SNP data from the public domain for studies of complex disorders: a test for ten candidate genes for obesity and osteoporosis. BMC Genet 5, 4.

22. Talwar SA, Aloia JF, Pollack S, et al. (2007) Dose response to vitamin D supplementation among postmenopausal African American women. Am J Clin Nutr 86, 1657-1662.

23. Nieves SH, Ralston E, Vásquez B, et al. (2007) Vitamin D receptor Fok1 polymorphism influences response to vitamin D supplementation in postmenopausal African-American women. Int Cong Series 1297, 126-132.

24. Gennari L, Becherini L, Masi L, et al. (1997) Vitamin D receptor genotypes and intestinal calcium absorption in postmenopausal women. Calcif Tissue Int 61, 460-463.

25. Abrams SA, Griffin IJ, Hawthorne KM, et al. (2005) Vitamin D receptor Fok1 polymorphisms affect calcium absorption, kinetics, and bone mineralization rates during puberty. J Bone Miner Res 20, 945-953.

26. Ferrari SL \& Rizzoli R (2005) Gene variants for osteoporosis and their pleiotropic effects in aging. Mol Aspects Med 26, $145-167$.

27. Somjen D (2007) Vitamin D modulation of the activity of estrogenic compounds in bone cells in vitro and in vivo. Crit Rev Eukaryot Gene Expr 17, 115-147.

28. Lee GS, Choi KC, Han HJ, et al. (2007) The classical and a non-classical pathways associated with NF-kappaB are involved in estrogen-mediated regulation of calbindin-D9k gene in rat pituitary cells. Mol Cell Endocrinol 277, 42-50.

29. Colin EM, Uitterlinden AG, Meurs JB, et al. (2003) Interaction between vitamin $\mathrm{D}$ receptor genotype and estrogen receptor alpha genotype influences vertebral fracture risk. J Clin Endocrinol Metab 88, 3777-3784.

30. Long J, Liu P, Zhang Y, et al. (2003) Interaction effects between estrogen receptor alpha gene, vitamin $\mathrm{D}$ receptor gene, age, and sex on bone mineral density in Chinese. J Hum Gene 48, 514-519.

31. Schwartz B, Smirnoff P, Shany S, et al. (2000) Estrogen controls expression and bioresponse of 1,25-dihydroxyvitamin D receptors in the rat colon. Mol Cell Biochem 203, 87-93.

32. Carling T, Ridefelt P, Hellman P, et al. (1997) Vitamin D receptor polymorphisms correlate to parathyroid cell function in primary hyperparathyroidism. J Clin Endocrinol Metab 82, 1772-1775.

33. Carling T, Kindmark A, Hellman P, et al. (1995) Vitamin D receptor genotypes in primary hyperparathyroidism. Nat Med 1, 1309-1311.

34. Yokoyama K, Shigematsu T, Kagami S, et al. (2001) Vitamin $\mathrm{D}$ receptor gene polymorphism detected by digestion with Apa I influences the parathyroid response to extracellular calcium in Japanese chronic dialysis patients. Nephron 89 , $315-320$. 
35. Cusack S \& Cashman KD (2003) Impact of genetic variation on metabolic response of bone to diet. Proc Nutr Soc 62, 901-912.

36. Miyao M, Morita H, Hosoi T, et al. (2000) Association of methylenetetrahydrofolate reductase (MTHFR) polymorphism with bone mineral density in postmenopausal Japanese women. Calcif Tissue Int 66, 190-194.

37. Abrahamsen B, Madsen JS, Tofteng CL, et al. (2003) A common methylenetetrahydrofolate reductase (C677T) polymorphism is associated with low bone mineral density and increased fracture incidence after menopause: longitudinal data from the Danish osteoporosis prevention study. J Bone Miner Res 18, 723-729.

38. Frost ML, Blake GM \& Fogelman I (2000) Can the WHO criteria for diagnosing osteoporosis be applied to calcaneal quantitative ultrasound? Osteoporos Int 11, 321-330.

39. von Elm E, Altman DG, Egger M, et al. (2007) STROBE initiative. The strengthening the reporting of observational studies in epidemiology (STROBE) statement: guidelines for reporting observational studies. Lancet 370, 1453-1457. 